\title{
Side Splitting Failure of RC Beams and Columns under Seismic Action As a Form of Shear Failure
}

\author{
Toshikatsu Ichinose $^{1^{*}}$ and Koshiro Nishimura ${ }^{2}$
}

\begin{abstract}
Recently bond splitting failure prior to the yielding of stirrups has attracted more attention for reinforced concrete (RC) structures located in seismic areas due to the increased popularity of high strength steel. However, bond splitting failure is complicated, particularly in RC beams with multiple layers of reinforcement with different cutoffs. Pullout tests indicate the bond strengths of bars in the second (inner) layer of $\mathrm{RC}$ beams are weaker than those in the first (outer) layer. In contrast, test results of RC beams indicate that the bond strengths of cutoff bars in the second layer are larger than those in the first layer. To examine this contradiction, previous studies of pullout test in which deformed bars were embedded in concrete were reviewed. In contrast to the conventional method of evaluating the surface bond strength of each bar, a new method for evaluating bond resistance is developed, in which a discussion point is focused on the shear strength at a potential failure plane below the reinforcement layer. The proposed method shows good results when compared with test results of RC beams and columns that failed in bond splitting prior to yielding of longitudinal reinforcement, with an average ratio of measured-to-predicted failure stress of 1.23 and a coefficient of variation of $14 \%$. In contrast, ACI 318-19 shear equation slightly underestimated some of the test results of single-layered beams, with an average ratio of measured-to-predicted failure stress of 0.98 and a coefficient of variation of $15 \%$. These findings suggest that side splitting failure of RC beams and columns under seismic action can be treated as shear failure.
\end{abstract}

\section{Introduction}

Figure 1 shows a beam in a nine-story building after the Great East Japan Earthquake, 2011. Horizontal crack is prominent along the bottom reinforcement. Similar cracks were observed in numerous beams of this building (Nagaya et al. 2013). This type of failure, which differs from a traditional flexural or shear failure, is also observed in laboratory and called "splitting bond failure (Fujii and Morita 1982)." This paper deals with such a failure.

Bond refers to the interaction between concrete and reinforcement. Studies of bond date back more than a century. In 1913, Abrams (1913) discussed many factors that affect bond strength (such as cover thickness) using 1511 pullout specimens, most of which were cylindrical with a bar at the center. Goto (1971) tested tensile specimens, each a single bar embedded in a long concrete prism and pulled at both ends. He reported fine cracks in front of each rib deformation of a bar as a result of bond stress. Fujii and Morita (1982), and Otani and Maeda (1994) tested pullout specimens as shown in Fig. 1a, each with a single layer of reinforcement comprising several bars. In this figure, the bars were bonded

\footnotetext{
${ }^{1}$ Professor, Meijo University, 1-501, Shiogamaguchi, Tenpaku, Nagoya, 468-8502, Japan.

*Corresponding author, E-mail: icht@meijo-u.ac.jp

${ }^{2}$ Associate Professor, Tokyo Institute of Technology, Nagatsuta 4259, \#R3-16, Midori, Yokohama, 226-8503, Japan.
}

to the concrete between $\mathrm{A}$ and $\mathrm{B}$, and small inclined cracks were observed in this region.

The tests of Fujii and Morita (1982), and Otani and Maeda (1994) provide a useful basis for introducing nomenclature and behavior. In these tests, the tensile stress of each bar was inferred using strain gages $\left(\sigma_{1}\right.$ in Fig. 2a). Bond strength was defined as the average shear strength at the interface of the concrete and reinforcement $\left(\tau_{\text {bu }}\right.$ in Fig. 2a), computed from the bar stress $\sigma_{1}$ and the embedment length $l_{d}$. The bond stress causes radial expansion shown in Fig. 2c, which causes a splitting bond failure as shown in Fig. 2d. Based on such observations, AIJ Codes (AIJ 1999, 2018) provide bond-splitting strength formulas, considering the effects of concrete strength, cover, spacing, and transverse reinforcement. ACI 318 (ACI 2019) similarly provides minimum requirement of development length, which is mostly based on studies from the 1970s (Jirsa et al. 1979). More recently, bond strength in lap splices has been the subject of much more attention (Canbay and Frosch 2005; Hardisty et al. 2015).

One difference between AIJ and ACI is the treatment of multiple layers of bars. When a large amount of longitudinal reinforcement is needed in a beam or column, reinforcing bars are arranged in two or more layers as shown in Figs. 2b and 3a. In pullout tests of deformed bars, bars arranged in multiple layers have been observed to have weaker bond strengths ( $\tau_{b u 1}$ and $\tau_{b u 2}$ in Fig. 1b) than bars in a single layer $\left(\tau_{b u}\right.$ in Fig. 1a) (Masuda et al. 1994; Ohyado et al. 1991; Nishimura and Onishi 2018). In the AIJ RC Standard (AIJ 2018) and the Inelastic Concept Guidelines (AIJ 1999), the bond 
strength in the second (inner) layer is reduced by $40 \%$ to account for this phenomenon. ACI 318 does not include such a factor, and multiple layers of reinforcing steel are treated the same.

The other difference between AIJ and ACI is the scope of formulas for bond strength. In AIJ, the formu-

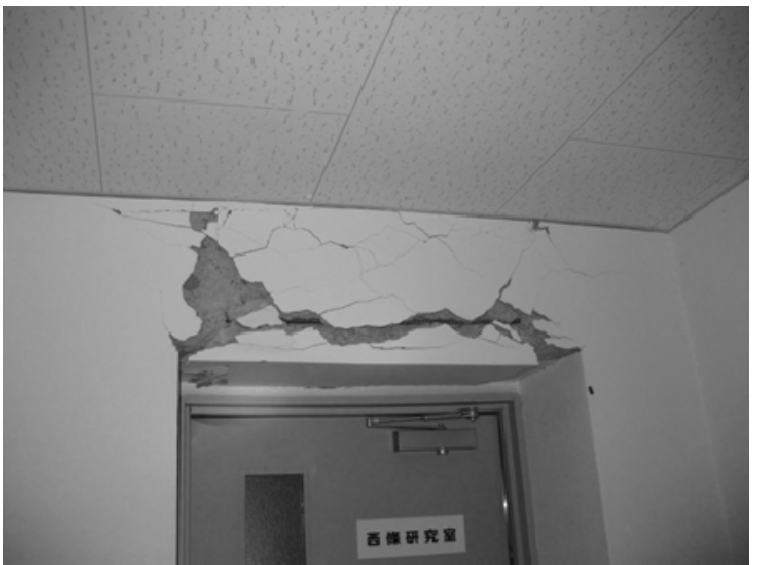

Fig. 1 Bond failure of beam (The Great East Japan Earthquake, 2011).
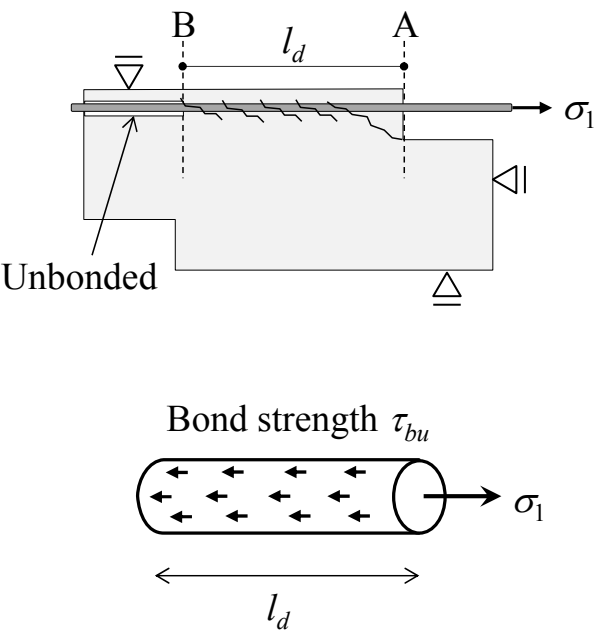

(a) Single layered bars

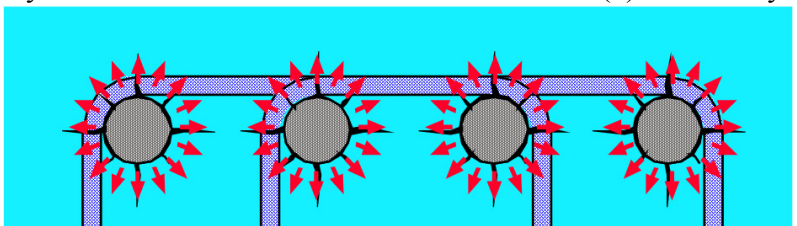

(c) Radial expansion of concrete

D

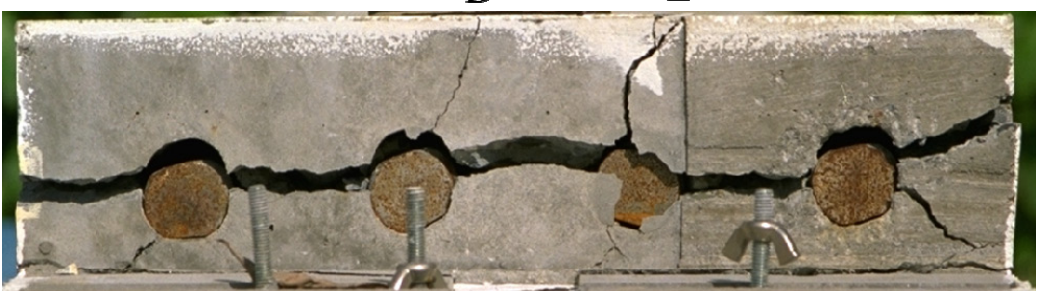

(d) Splitting bond failure

Fig. 2 Pull out test of longitudinal bars embedded in concrete. las have been applied to both columns and beams since 1990 (AIJ 2018), because the importance of bond splitting failure (Fig. 1) of columns and beams has been recognized in Japan since the 1980s (Muguruma and Watanabe 1984). In ACI 318, bond strength formulas have long been used to determine the minimum requirement of development and splice lengths of reinforcing bars terminated in beams. But for the first time in 2019, ACI 318 Section 18.7.4.3 for EarthquakeResistant Structures was revised so that the formulas are also applied to bars of columns to avoid bond splitting failure during earthquakes (ACI 2019; Ichinose 1995; Sokoli and Ghannoum 2016).

Figure 3a conceptually shows a beam with two layers of reinforcement subjected to anti-symmetric bending and shear which failed in bond before flexural yielding. In Fig. 3a, ${ }_{T} \sigma_{1}$ and ${ }_{C} \sigma_{1}$ are the tensile and compressive stresses in the outer (first) layer at both beam ends, and ${ }_{T} \sigma_{2}$ and ${ }_{C} \sigma_{2}$ are those in the inner (second) layer, respectively. Figure 3b shows stress diagram for the bar in the top two layers, where the stress in the second layer (light gray) is stacked on the stress in the first layer (dark gray). Note that the compressive stresses in
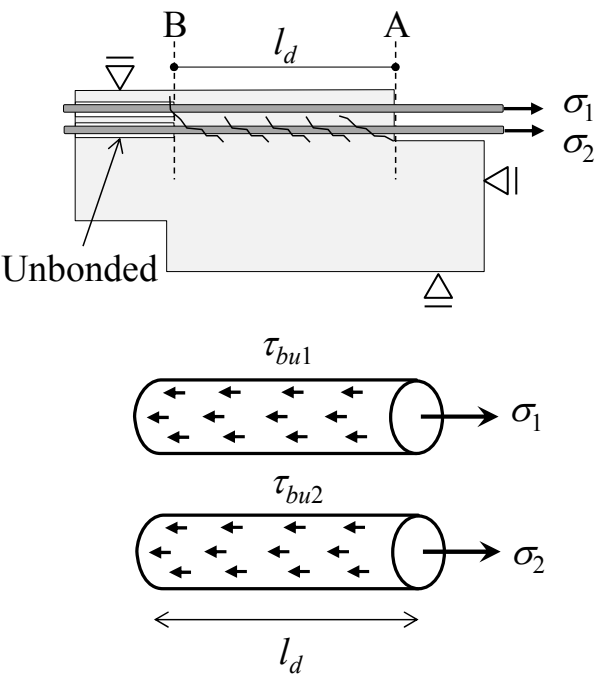

(b) Double layered bars 
the bars are smaller than the tensile stresses because of the contribution of the concrete in compression. Figure 3c shows the distribution of bond stress. The observed bond stresses of inner bars (Ito et al. 2013; Shinohara and Murakami 2015) at failure ( $\tau_{b 2}$ in Fig. 3c) are like those observed in pullout tests of specimens with two layers $\left(\tau_{b u 2}\right.$ in Fig. 1b).

Figure 3 shows an idealized case in which the longitudinal reinforcement is continuous, but in actuality bars are terminated at different points along a span depending on demands and available lengths. Bond of multilayered beams with such bar terminations is more complex than this ideal. Figure 4a illustrates the case shown in Fig. 3 but with bars terminated near the center of the span. The bending moment is assumed to be the same as that in Fig. 3a. An idealized stress distribution of the bars is shown in Fig. $\mathbf{4 b}$, where the sum of the stresses of the outer and inner bars is the same as those in Fig. 3b because the bending moment is equal. One different feature in Fig. 4b compared with Fig. $\mathbf{3 b}$ is that the tensile stress of the inner bars is zero at section $\mathrm{B}$, where the bars are terminated. This stress distribution results in larger bond stresses in the inner bars between B and A as shown in Fig. 4c, where the bond stress of the outer bars is zero. Despite these larger bond stresses, bond failures have seldom been observed in the region be-

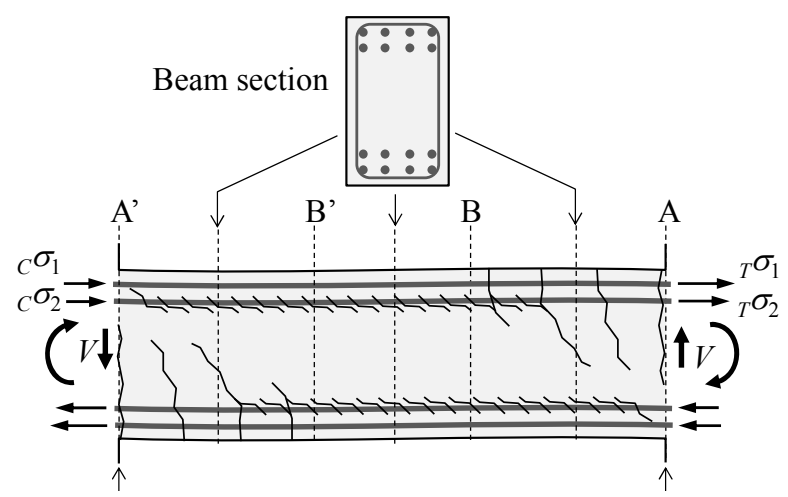

Boundary with column

Boundary with column

(a) $\mathrm{R} / \mathrm{C}$ beam subjected to bending and shear

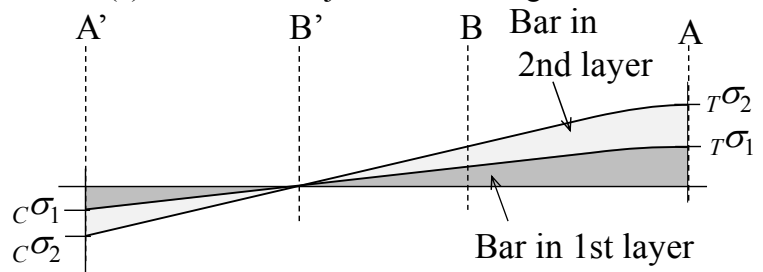

(b) Stress distribution diagram of top double bars

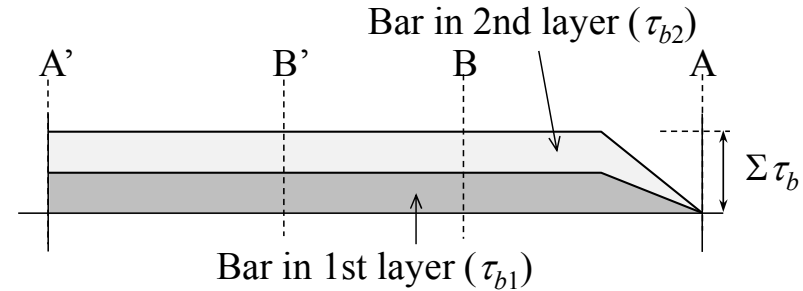

(c) Bond stress diagram of top double layers

Fig. $3 \mathrm{R} / \mathrm{C}$ beam with double layers of reinforcing bars passing through span. tween B and A (Ito et al. 2013; Shinohara and Murakami 2015). Splitting bond failure usually occurs between B' and B, as shown in Fig. 4a. The observed bond stresses of such bars between B' and B are similar to those observed in the pullout test with a single layer $\left(\tau_{b u}\right.$ in Fig. 2a) (Ito et al. 2013; Shinohara and Murakami 2015).

In this paper, the authors examine bond capacity of bars arranged in two or more layers from a different perspective. The conventional definition (defining bond stress as the shear stress on the surface of a bar) is effective for pullout of a bar embedded in solid concrete. For bond failures like those shown in Figs. 1 through 4, however, evaluating shear stress on the potential splitting plane of multi-layered bars may be more convenient. In this paper, previous pullout test results and bending-shear test results are reviewed in order to evaluate bond performance of RC beams with multiple layers of longitudinal bars including cut-off bars. Application to RC columns is also discussed.

Beside the side-splitting bond failure shown in Fig. 2d, corner splitting failure may occur if one-half of bar spacing is larger than clear cover (Jirsa et al. 1979). However, this paper deals with side splitting only and not corner splitting because of the following two rea-

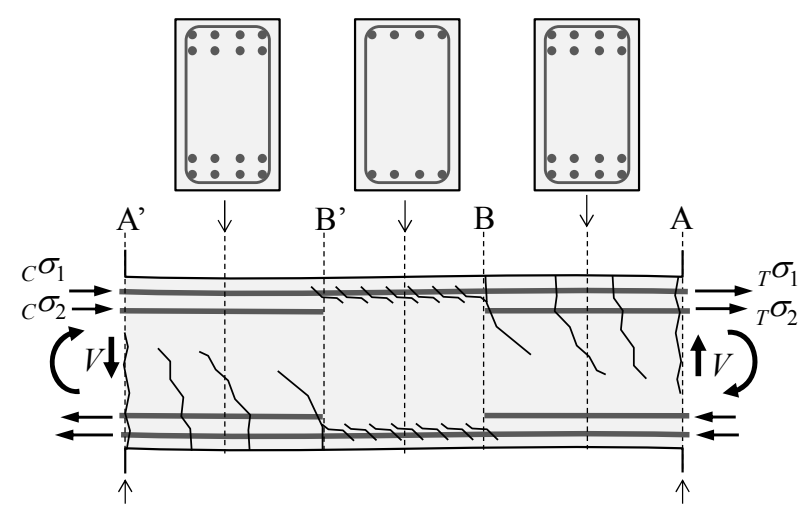

Boundary with column Boundary with column (a) $\mathrm{R} / \mathrm{C}$ beam subjected to bending and shear

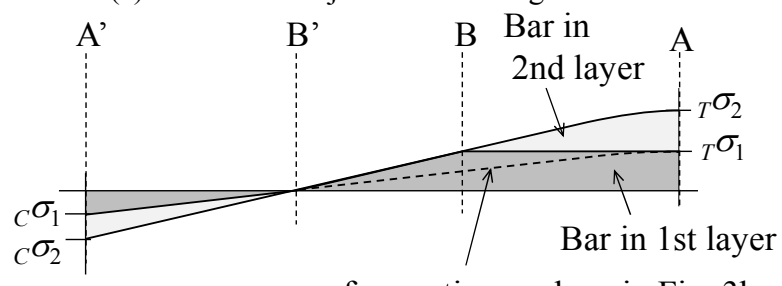

${ }_{T} \sigma_{1}$ for continuous bars in Fig. 3b

(b) Stress distribution diagram of top double bars

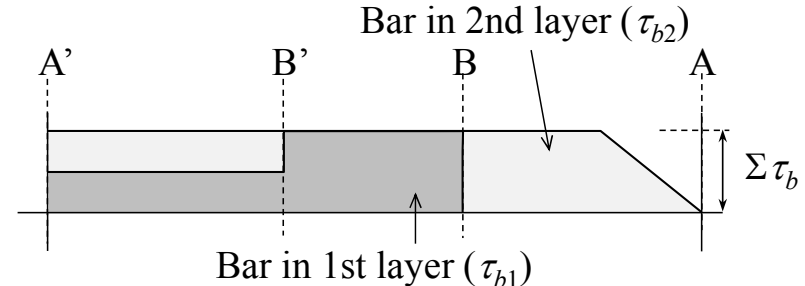

(c) Bond stress diagram of top double layers

Fig. 4 R/C beam with cut-off bars in second layer. 
sons: (1) corner splitting is rarely reported in tests of beams and columns with continuous bars or reconnaissance reports of seismic damages probably because corner splitting strength is large enough unless the bar diameter is too large; (2) corner splitting can be easily avoided by the conventional method.

\section{Review of pull out test results}

In this paper, the observed bond splitting failures shown in Figs. 2a and $\mathbf{2 b}$ are simplified as shown in Figs. 5a and $\mathbf{5 b}$. When there are fewer bars in the second layer compared with the first layer, the failure may occur in the first layer as shown in Fig. 5c. For simplicity, the failures shown in Figs. 5a and $\mathbf{5 b}$ will be discussed first; the case of Fig. 5c will be considered later. Fig. 6a shows the proposed concept of the failure. Slip of the bars after splitting is assumed to cause failure at the dark region below the splitting plane in Fig. 6a. Shear stress on the failure plane is defined as shown in Fig. $6 \mathbf{b}$, with shear strength denoted as $\tau_{s u}=\left(T_{s 1}+T_{s 2}\right) /\left(b \times l_{d}\right)$.
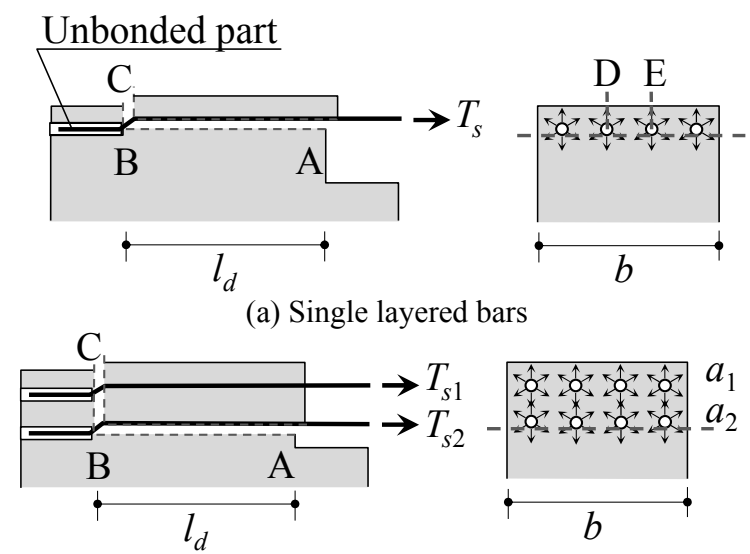

(b) Bond failure at second layer

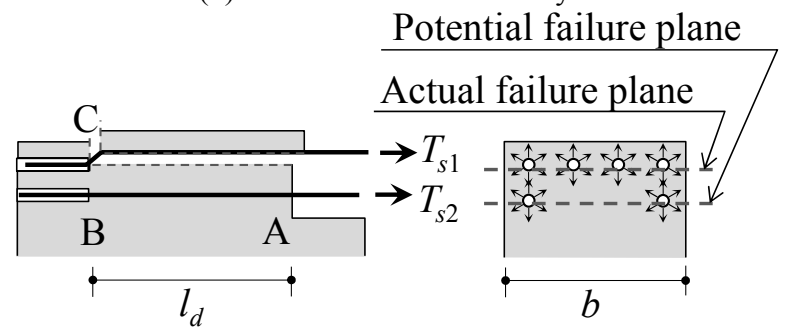

(c) Bond failure at first layer of double layered bars

Fig. 5 Failure in pullout test.

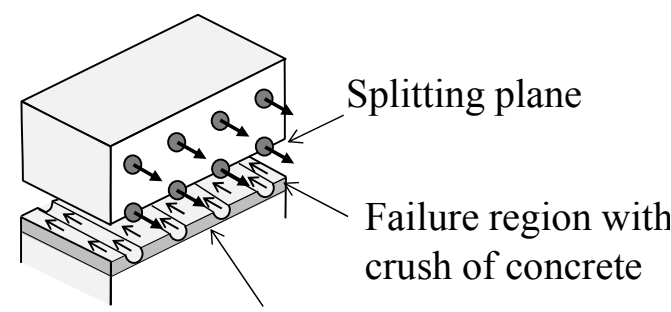

Failure plane

(a) Failure plane
This definition is quite different from the conventional definition shown in Figs. 2a and $\mathbf{2 b}$, with bond strength denoted as $\tau_{b u}$.

There have been many pullout tests of deformed bars arranged in single and double layers. Table 1 summarizes data of tests conducted in Japan on specimens like those shown in Fig. 2. The specimens of Masuda et al. (1994) listed in the first row of Table $\mathbf{1}$ had a special feature: two bars in the first layer and three bars in the second layer as shown inside Fig. 7. Six specimens were tested, where the parameter was the ratio of $T_{s 1} / T_{s 2}$ from 0 to 0.67 as shown in the horizontal axis of Fig. 7: e.g., in the case of the specimen with $T_{s 1} / T_{s 2}=0$, only the bars in the second layer were pulled. No transverse reinforcement was provided. All the specimens failed in bond-splitting at the second layer. The solid squares in Fig. 7 show the bond stress in the second layer bars $\tau_{b u 2}$ defined by Fig. 2b, which decreases as $T_{s 1} / T_{s 2}$ increases. The open squares in Fig. 7 show the shear stress of the failure plane $\tau_{s u}$ defined by Fig. $\mathbf{6 b}$. The $\tau_{s u}$ slightly increases as $T_{s 1} / T_{s 2}$ increases for lower $T_{s 1} / T_{s 2}$ than around 0.3 , and becomes constant for larger $T_{s 1} / T_{s 2}$. For simplicity, we assume that the shear strength on the failure plane at the second layer is constant even if the bond stress around the first layer changes.

Next, the difference of $\tau_{s u}$ between single and double layers of reinforcement is examined. In Fig. 8, the vertical axis is $\tau_{s u}$ and the horizontal axis is transverse reinforcement ratio, $\rho_{t}$, which is defined as:

$$
\rho_{t}=a_{w} /(b s)
$$

where $a_{w}$ is cross-sectional area of the transverse bars crossing horizontal section of $b s, b$ is beam width, and $s$ is the spacing of transverse reinforcement. "Top" and "bottom" in Fig. 8 refer to the locations of longitudinal bars with reference to the casting direction of concrete. Lightweight concrete with a specified compressive strength of $f^{\prime}{ }_{c}=36 \mathrm{MPa}$ (5200 psi) was used for the specimens so that the bond strengths would be smaller. Other properties of the specimens are summarized in the second row of Table 1 (Ohyado et al. 1991). As shown in Fig. 8, the shear strengths $\left(\tau_{s u}\right)$ of the top bars (the triangles) were smaller than those of the bottom bars (the squares); this effect is well known and is introduced in many design codes (ACI 2019: AIJ 2018). More importantly, the shear strengths of the double-layered specimens (the solid lines) were larger than those of the

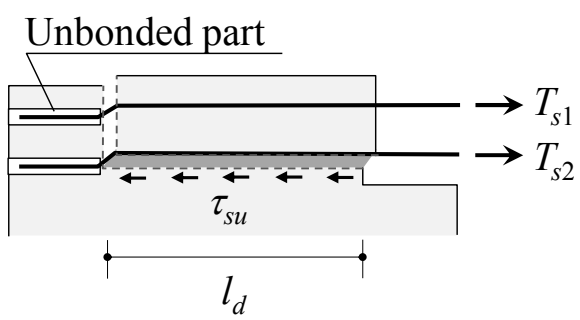

(b) Shear strength on failure plane $\tau_{s u}$

Fig. 6 Failure plane and definition of strengths. 
Table 1 Test data of pull out tests in previous study.

\begin{tabular}{|c|c|c|c|c|c|c|c|c|c|}
\hline \multirow{2}{*}{ Ref. } & \multirow{2}{*}{$\begin{array}{l}\text { Name of } \\
\text { specimen }\end{array}$} & \multirow{2}{*}{$f_{c m}{ }^{\dagger} \mathrm{MPa}$} & \multirow{2}{*}{$b, \mathrm{~mm}$} & \multirow{2}{*}{$\begin{array}{c}l_{d} \\
\mathrm{~mm}\end{array}$} & \multirow{2}{*}{$\begin{array}{c}\text { Transverse } \\
\text { reinforcement }\end{array}$} & \multicolumn{2}{|c|}{ Longitudinal bars } & \multicolumn{2}{|c|}{ Test results, kN } \\
\hline & & & & & & $1^{\text {st }}$ layer & $2^{\text {nd }}$ layer & $T_{s 1}$ & $T_{s 2}$ \\
\hline \multirow{6}{*}{ Masuda et al. 1994} & DCL0-0 & \multirow{2}{*}{35.6} & \multirow{6}{*}{200} & \multirow{6}{*}{500} & \multirow{6}{*}{$\rho_{t}=0 \%$} & \multirow{6}{*}{$2-\mathrm{D} 23$} & \multirow{6}{*}{$3-\mathrm{D} 23$} & 0 & 225 \\
\hline & DCL23-0 & & & & & & & 45 & 196 \\
\hline & DCL33-0 & \multirow{4}{*}{37.7} & & & & & & 65 & 197 \\
\hline & DCL47-0 & & & & & & & 84 & 180 \\
\hline & DCL55-0 & & & & & & & 97 & 177 \\
\hline & DCL67-0 & & & & & & & 105 & 157 \\
\hline \multirow{10}{*}{ Ohyado et al. 1991} & No.2T & $\begin{array}{c}35.3 \\
\text { light- } \\
\text { weight }\end{array}$ & \multirow{10}{*}{415} & \multirow{10}{*}{580} & $\begin{array}{c}\text { 2-D10@60mm, } \\
\rho_{t}=0.57 \%\end{array}$ & \multirow{5}{*}{$\begin{array}{l}\text { 4-D29, } \\
\text { top bar }\end{array}$} & \multirow{3}{*}{ N/A } & 604 & \multirow{3}{*}{ N/A } \\
\hline & No.11T & \multirow{4}{*}{$\begin{array}{c}37.2 \\
\text { light- } \\
\text { weight }\end{array}$} & & & $\rho_{t}=0 \%$ & & & 351 & \\
\hline & No.12T & & & & $\begin{array}{c}\text { 2-D10@120mm, } \\
\rho_{t}=0.29 \%\end{array}$ & & & 471 & \\
\hline & No.15T & & & & $\rho_{t}=0 \%$ & & \multirow[b]{2}{*}{$\begin{array}{l}\text { 4-D29, } \\
\text { top bar }\end{array}$} & 319 & 327 \\
\hline & No.16T & & & & $\begin{array}{c}2-\mathrm{D} 10 @ 120 \mathrm{~mm}, \\
\rho_{t}=0.29 \%\end{array}$ & & & 363 & 374 \\
\hline & No.2B & $\begin{array}{c}35.3 \\
\text { light- } \\
\text { weight }\end{array}$ & & & $\begin{array}{c}2-\mathrm{D} 10 @ 60 \mathrm{~mm}, \\
\rho_{t}=0.57 \%\end{array}$ & & $N / 4$ & 727 & $N / 4$ \\
\hline & No.11B & \multirow{4}{*}{$\begin{array}{c}37.2 \\
\text { light- } \\
\text { weight }\end{array}$} & & & $\rho_{t}=0 \%$ & & N/A & 421 & N/A \\
\hline & No.12B & & & & $\begin{array}{c}2-\mathrm{D} 10 @ 120 \mathrm{~mm}, \\
\rho_{t}=0.29 \%\end{array}$ & 4-D29 & & 505 & \\
\hline & No.15B & & & & $\rho_{t}=0 \%$ & & & 367 & 372 \\
\hline & No.16B & & & & $\begin{array}{c}\text { 2-D10@120mm, } \\
\rho_{t}=0.29 \%\end{array}$ & & 4-D29 & 405 & 417 \\
\hline \multirow{9}{*}{$\begin{array}{l}\text { Nishimura and } \\
\text { Onishi } 2018\end{array}$} & 2C3C3-F24 & 25.3 & \multirow{9}{*}{200} & \multirow{9}{*}{500} & $\begin{array}{c}\text { 2-D6@160mm, } \\
\rho_{t}=0.20 \%\end{array}$ & & \multirow{3}{*}{ 3-D19 } & 187 & 134 \\
\hline & $4 \mathrm{C} 3 \mathrm{C} 3-\mathrm{F} 24$ & 27.3 & & & $\begin{array}{c}\text { 2-D6@80mm, } \\
\rho_{t}=0.40 \%\end{array}$ & & & 256 & 180 \\
\hline & 6C3C3-F24 & 26.2 & & & $\begin{array}{c}\text { 2-D10@118mm, } \\
\rho_{t}=0.60 \%\end{array}$ & & & 301 & 202 \\
\hline & 2C3-F21 & 20.1 & & & & $3-019$ & & 196 & \\
\hline & 2C3-F36 & 37.0 & & & $\rho_{t}=0.20 \%$ & & & 266 & \\
\hline & 2C3-F54 & 52.7 & & & & & N/A & 352 & N/A \\
\hline & 4C3-F21 & 20.1 & & & & & N/A & 276 & N/A \\
\hline & 4C3-F36 & 37.0 & & & 2-D0@,oumm, & & & 365 & \\
\hline & 4C3-F54 & 52.7 & & & & & & 442 & \\
\hline & $4.0 \mathrm{t} 2-\mathrm{C} 4 \mathrm{C} 4$ & 30.7 & & & $\begin{array}{c}\text { 2-D6@45mm, } \\
\rho_{t}=0.40 \%\end{array}$ & 4-D19 & 4-D19 & 432 & 296 \\
\hline Nishimura and & $4.0 \mathrm{t} 3-\mathrm{C} 5 \mathrm{C} 3$ & 28.2 & & & $\begin{array}{c}\text { 3-D6@68mm, } \\
\rho_{t}=0.40 \%\end{array}$ & 5-D19 & 3-D19 & 507 & 200 \\
\hline Kawazu 2020 & $4.0 \mathrm{t} 3-\mathrm{C} 5 \mathrm{C} 2$ & 26.6 & 350 & 500 & $\begin{array}{c}\text { 3-D6@68mm, } \\
\rho_{t}=0.40 \%\end{array}$ & 5-D19 & 2-D19 & 469 & 128 \\
\hline & 4.0t4-C4C4 & 30.2 & & & $\begin{array}{c}\text { 4-D6@90mm, } \\
\rho_{t}=0.40 \%\end{array}$ & 4-D19 & 4-D19 & 497 & 309 \\
\hline
\end{tabular}

*Bar designation numbers following "D" are nominal diameters in millimeter; "top bar" means bars near top surface of concrete in casting direction.

†Measured compressive strength of concrete cylinder; "lightweight" means light weight concrete and others are normal weight concrete.

Notes: $b$ is width of specimen; $\rho_{t}$ is transverse reinforcement ratio (Eq. 1); $l_{d}$ is embedment length of the bars; $T_{s 1}$ and $T_{s 2}$ are maximums of total tension load on bars in $1^{\text {st }}$ and $2^{\text {nd }}$ layer, respectively (See Fig. 3).

single-layered specimens (the broken lines). In the authors' understanding, this effect is attributable to the difference of failure pattern: vertical cracks ( $D$ and $E$ in Figs. 2d or 5a) can form in the cover concrete of singlelayered specimens resulting in the convex upwards deformation of the cover concrete, whereas these cracks rarely occur in the case of double-layered specimens as shown in Fig. 6a.
Regarding the effect of transverse reinforcement in Fig. 8, the slope of $\tau_{s u}$ with respect to $\rho_{t}$ is almost the same even if the number of layers and the location of the bars are different. Similar results can be seen in Fig. 9, where the axes are the same as Fig. 8, but the test data come from different specimens (Nishimura and Onishi 2018 in Table 1) made of normal-weight concrete with a range of compressive strengths. Fig. 9 
shows that the slopes of $\tau_{s u}$ with respect to $\rho_{t}$ are similar even if the concrete strengths are different.

Figure 10 shows how concrete weight affects the slope of $\tau_{s u}$ with respect to $\rho_{t}$, where the axes and the markers of the specimens are same as those in Figs. 8 and 9. At a reinforcement ratio of $0.2 \%$, the curves for lightweight concrete and normal-weight concrete intersect, but the strength of the lightweight concrete was 36 MPa compared with 21-24 MPa for the normal-weight concrete. Not surprisingly, this suggests that the shear strength of lightweight concrete is smaller than that of normal-weight concrete of the same compressive strength. In addition, as shown in Fig. 10, the slopes of shear strength with respect to transverse reinforcement ratio for lightweight concretes are shallower than those for normal-weight concrete: that is, transverse reinforcement may be less effective at increasing shear strength in lightweight concrete.

The above observations can be summarized as follows.

(1) Bond strength $\left(\tau_{b u}\right)$ in the second layer is sensitive to bond stress in the first layer, but shear strength $\left(\tau_{s u}\right)$ is insensitive to changes in bond stress in the first layer (Fig. 7).

(2) While $\tau_{s u}$ of the double-layered specimens are larger than those of the single-layered specimens, the

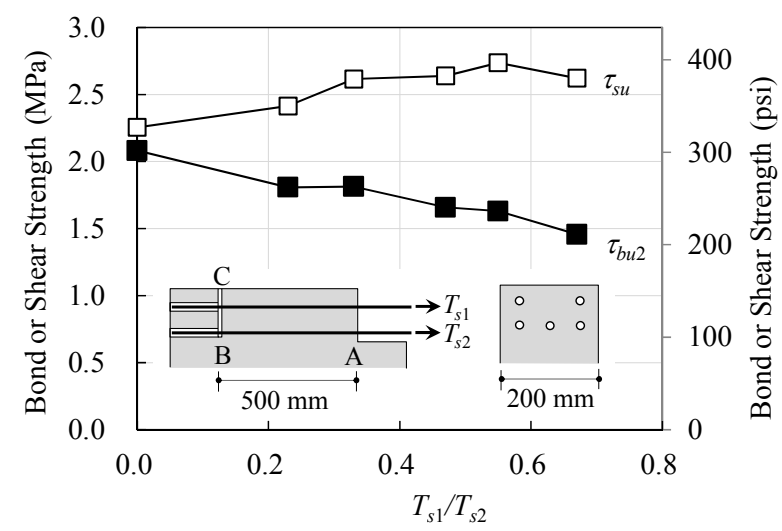

Fig. 7 Influence of tensile force in first layer on bond splitting at second layer.

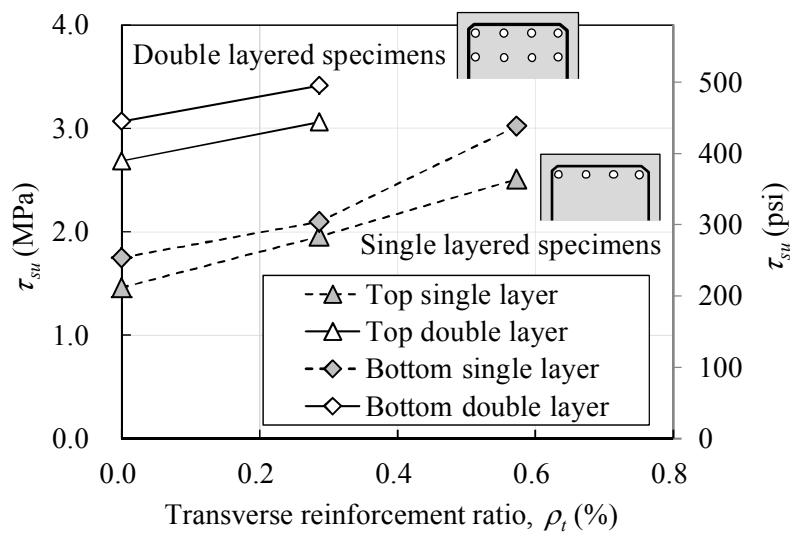

Fig. 8 Difference of $\tau_{s u}$ between single and double layered specimens. slopes of $\tau_{s u}$ with respect to $\rho_{t}$ are almost the same even if the number of layers, casting location of the bars, and concrete strength are different (Figs. 8 and 9).

(3) The $\tau_{s u}$ of lightweight concrete is lower than that of normal weight-concrete of the same concrete strength. In addition, the slope of $\tau_{s u}$ with respect to $\rho_{t}$ of lightweight concrete is shallower than that of normal-weight concrete (Fig. 10).

\section{Bond capacity formula}

Considering the observations above, the following formula is developed for the shear strength, $\tau_{s u}$. As discussed in Appendix, this formula is based on the equation for bond strength $\left(\tau_{b u}\right)$ in AIJ Inelastic Concept Guidelines (AIJ 1999) which is similar to the equation given by Jirsa et al. (1979), a basis of ACI 318 (ACI 2019).

$$
\tau_{s u}=\lambda \alpha_{t}\left\{0.33 \alpha_{l} \sqrt{f_{c}{ }^{\prime}}+180\left(1.2+\frac{N_{t}}{N}\right) \rho_{t}\right\}
$$

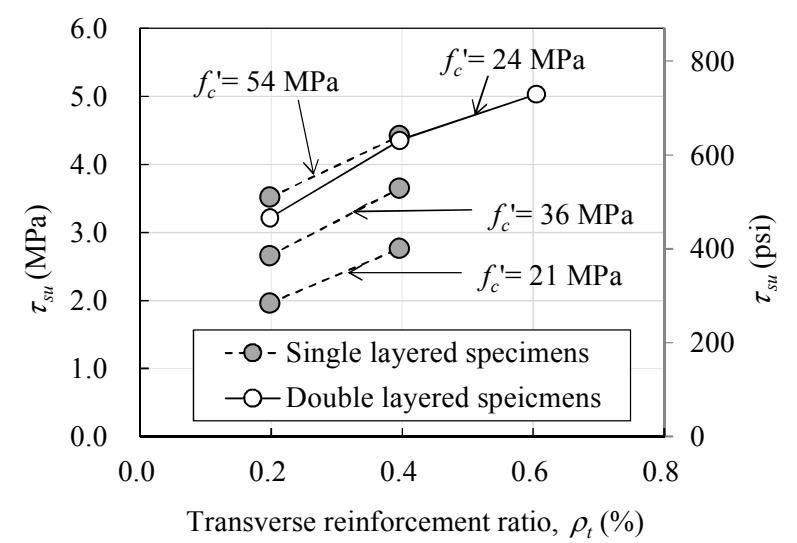

Fig. 9 Influence of concrete strength on increasing effect of transverse reinforcement.

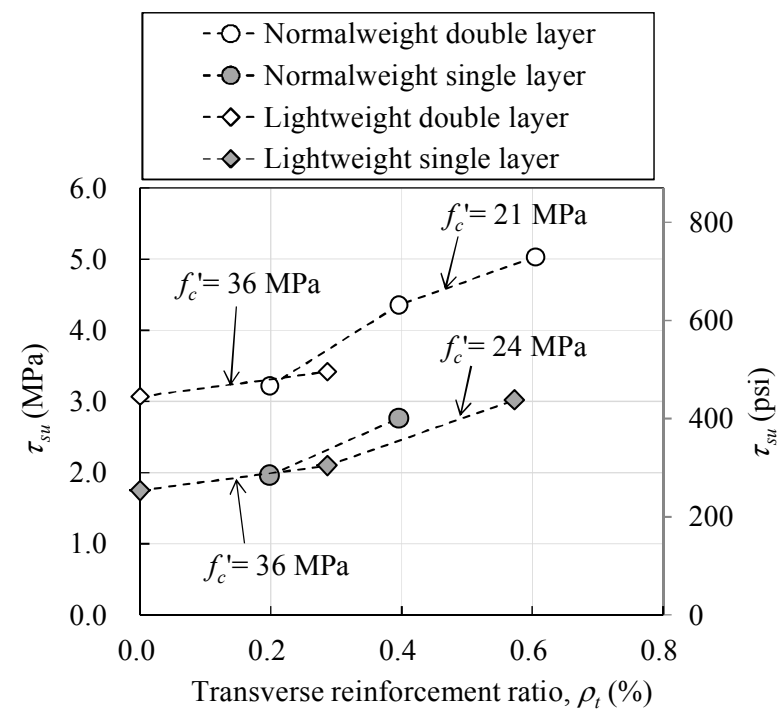

Fig. 10 Influence of concrete weight. 
where

$\lambda$ : reduction factor for light-weight concrete $(=0.8$ for light-weight and 1.0 for normal-weight concrete), $\alpha_{t}$ : reduction factor for top bars:

$$
\begin{aligned}
& \alpha_{t}=0.75+\frac{f_{c}{ }^{\prime}}{400} \leq 1 \text { for top bars, and } \\
& \alpha_{t}=1 \text { for other bars }
\end{aligned}
$$

$\alpha_{l}$ : enhancement factor for multiple-layer bars:

$$
\alpha_{l}=1+\frac{a_{2}}{a_{1}} \leq 1.5
$$

where $a_{1}$ and $a_{2}$ are the area of first- and second-layer bars, respectively,

$f_{c}$ ': compressive strength of concrete (MPa),

$N_{t}$ : number of longitudinal bars next to vertical legs of transverse reinforcement (Fig. 11),

$N$ : total number of longitudinal bars, and

$\rho_{t}$ : transverse reinforcement ratio (Eq. 1).

Figure 12 compares the test results of Table 1 and the calculations by Eq. 2 . The vertical axis is the ratio of the test result to the calculation, and the horizontal axis

The number of all the bars is $N=10$.

The number of white bars is $N_{t}=8$.

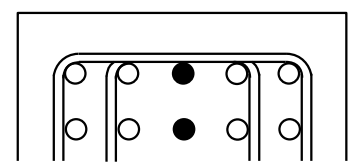

: Bar that is not next to tie

$O$ : Bar that is next to tie

Fig. 11 Example of counting bars next to transverse reinforcement. is the transverse reinforcement ratio. The markers of the specimens are the same as in Figs. 7, 8, 9, and 10. The specimens denoted by white square markers in Fig. 12 had slits from $\mathrm{B}$ to $\mathrm{C}$ shown in Fig. 7 to induce failure at that location $^{12}$, which could explain why the results were less conservative than the other specimens. Overall, the calculations show good agreement with the test results, with a mean ratio of test result to calculation of 1.02 , and a coefficient of variation of $13 \%$.

\section{Shear resistance of beam and column corresponding to side splitting}

In the preceding sections, failures of pullout specimens were discussed. In this section, side splitting failures in beams subjected to anti-symmetric bending and shear are discussed. Figure 13a shows simplified sidesplitting failure in beam with continuous two layers of

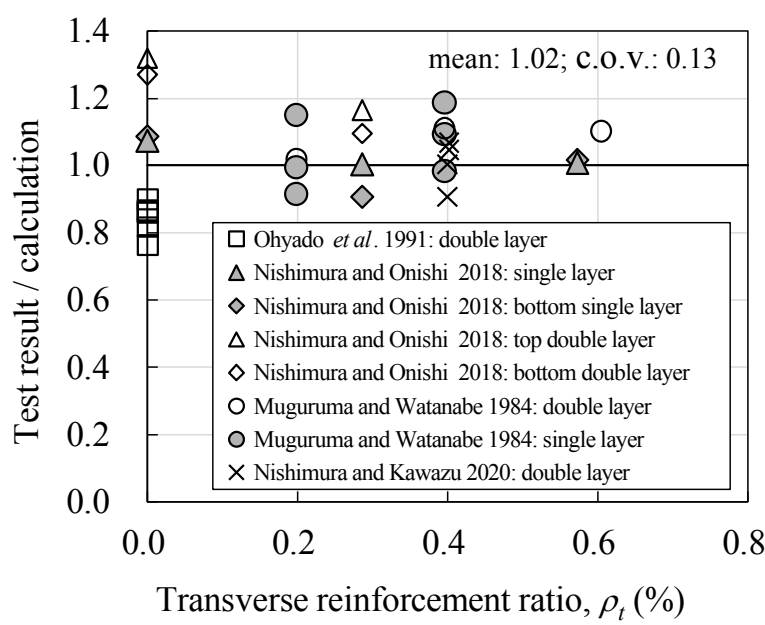

Fig. 12 Comparison between pullout test results and calculations.

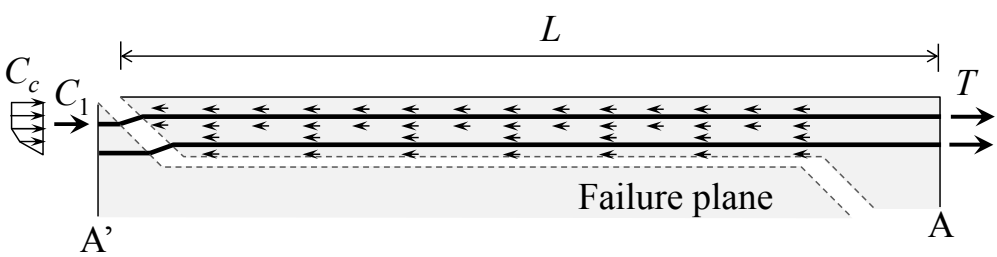

(a) Failure under second layer (possible)

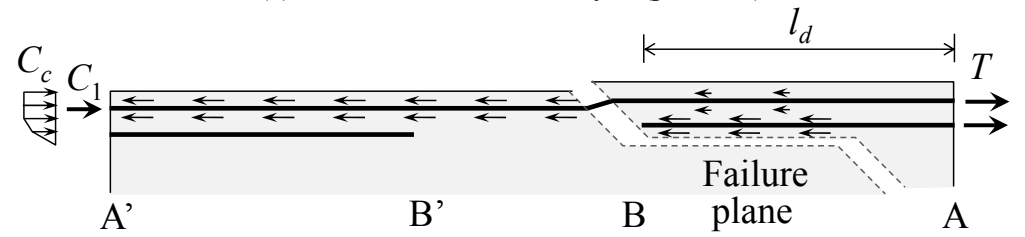

(b) Failure under cut off bars (less probable)

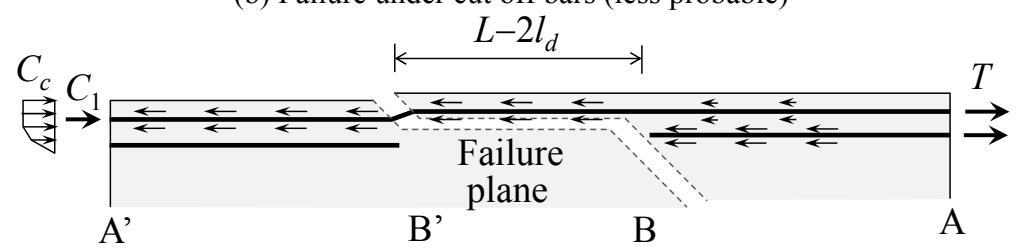

(c) Failure where bars are reduced (more probable)

Fig. 13 Bond failures in beams with double layered bars. 
longitudinal bars, corresponding to Fig. 3a. In a beam with cutoff as shown in Fig. 4a, two types of failure as shown in Figs. 13b and 13c are theoretically possible. However, the failure in Fig. 13b is less probable than that in Fig. 13c as will be discussed later.

Figure 14a shows a truss model for shear resistance of a part in beam between both end regions, which is defined by Schlaich et al. (1987), where the effect of flexural crack or dowel action can be neglected. The

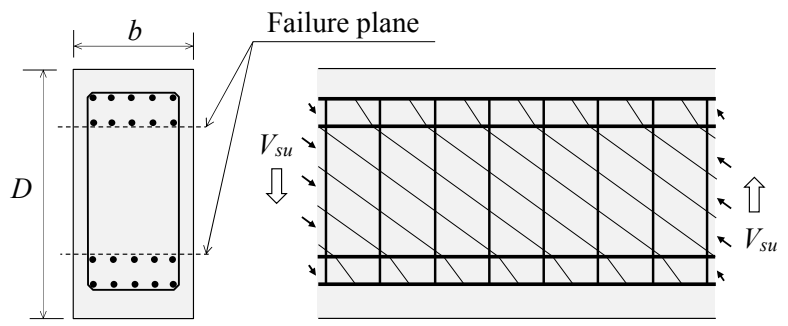

(a) Truss action in beam
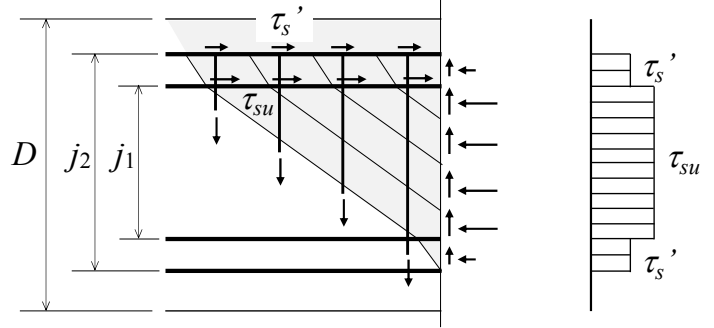

(b) Stress equilibrium

Shear stress diagram

(c) Shear stress in cross section

Axis at centroid of top bars

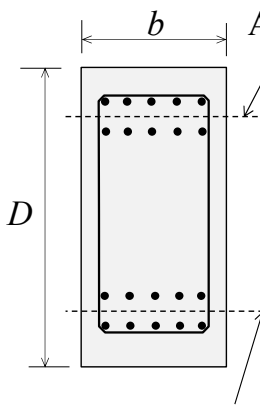

Axis at centroid of

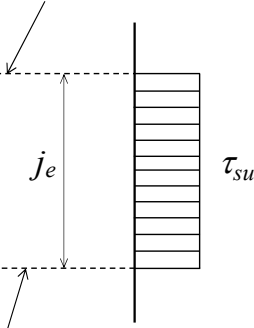

Simplified shear bottom bars

(d) Simplified shear stress distribution

Fig. 14 Shear resistance mechanism of beam which fails in bond. shear stress of the failure plane in the second layer is assumed to reach $\tau_{s u}$ as shown in Fig. 14b. The angle of the concrete strut depends on the tensile stress in the transverse reinforcement. Because of equilibrium, however, the shear stress in the cross-section of beam is equal to the shear stress on the horizontal failure plane as shown in Fig. 14c. As discussed in the previous section, the shear stress on the potential failure plane in the first (outer) layer ( $\tau_{s u}$ ' in Fig. 14b) is smaller than that on the actual failure plane at second layer, which results in the stepped diagram shown in Fig. 14c. The distribution in Fig. 14c can be simplified as shown in Fig. 14d; it is assumed that $\tau_{s u}$ is distributed over the crosssectional area of $b j_{e}$ where $b$ is the beam width and $j_{e}$ is the distance between the centroids of the top and the bottom longitudinal bars. This leads to the following shear capacity equation:

$$
V_{s u}=b j_{e} \tau_{s u}
$$

As mentioned in Appendix, a beam is expected to fail in the first layer when $1+a_{2} / a_{1}<1.5$ : that is, when the number of bars in the second layer is less than a half of the number of bars in the first layer. However, Eq. 5 is also applicable to this case because $\tau_{s u}$ in Eq. 2 represents the shear stress at the second layer.

Figure 15 shows a beam in which all the bars in the second layer are terminated in the span. In this case, shear capacities can be calculated at two sections:

(1) The capacity at section X (Fig. 15, left) associated with the failure in Fig. 13c, which is given by:

$$
V_{s u X}=b j_{e X} \tau_{s u X}
$$

(2) The capacity at section Y (Fig. 15, right) associated with the failure Fig. 13b, which is given by:

$$
V_{s u Y}=b j_{e Y} \tau_{s u Y}
$$

The shear capacity of the beam would be the smaller of these two values. However, in most cases, $V_{s u X}$ is smaller than $V_{s u Y}$, because $\alpha_{l}$ in Eq. 4 is usually larger than the ratio of $j_{e Y} / j_{e X}$. Thus, the failure in Fig. 13c is more probable than that in Fig. 13b. This tendency is reported in all the studies dealing with beams with cutoff bars in Table 2 (Ito et al. 2013; Shinohara and Murakami 2014, 2015; Suzuki et al. 2015; Kim et al. 2002;

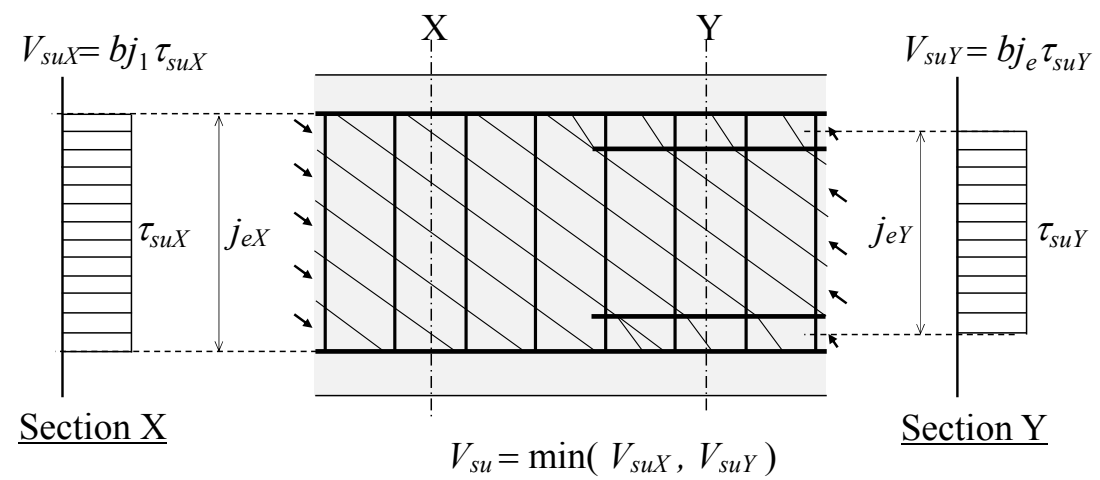

Fig. 15 Shear capacity of beam with cut-off bars. 
Table 2 Beam specimens failed in bond-splitting in previous study.

\begin{tabular}{|c|c|c|c|c|c|c|c|}
\hline Reference & Arrangements & $\begin{array}{c}\text { Width } b, \\
\text { mm }\end{array}$ & $\begin{array}{l}\text { Depth } h, \\
\text { mm }\end{array}$ & $M /(V d)^{*}$ & $f_{c m}, \mathrm{MPa}$ & $\rho_{w}(\%)$ & $\rho_{t}(\%)$ \\
\hline $\begin{array}{l}\text { Takami and Eto } 1999 ; \\
\text { Suzuki et al. } 2015 ; \\
\text { Kamitani et al. } 2001 ; \\
\text { Katori et al. } 1988 ; \\
\text { Kaminosono et al. } 1992\end{array}$ & Single layer & $180-200$ & $180-650$ & $1.6-3.6$ & $22.9-81.3$ & $0.85-2.39$ & $0.15-1.21$ \\
\hline $\begin{array}{c}\text { Shinohara and Murakami } 2015 ; \\
\text { Takami and Eto } 1999 ; \\
\text { Suzuki et al. } 2015 ; \\
\text { Kamitani } \text { et al. } 2001 ; \\
\text { Kaminosono et al. } 1992 ; \\
\text { Kim et al. } 2002 ; \\
\text { Masuda et al. } 1996 ; \\
\text { Takeuchi et al. } 1993 \text {; } \\
\text { Miyata et al. } 2018 \\
\end{array}$ & Double layers & $180-270$ & $270-650$ & $1.9-3.6$ & $22.9-81.3$ & $1.57-4.17$ & $0.28-1.14$ \\
\hline Takami and Eto 1999 & $\begin{array}{l}\text { More than two } \\
\text { layers }\end{array}$ & 200 & 650 & $2.3-2.4$ & $68.4-73.7$ & $5.38-9.30$ & 0.53 \\
\hline $\begin{array}{c}\text { Ito et al. 2013; } \\
\text { Shinohara and Murakami 2015; } \\
\text { Suzuki et al. 2015; Kim et al. 2002; } \\
\text { Shinohara and Murakami 2014; } \\
\text { Miyata } \text { et al. } 2018\end{array}$ & $\begin{array}{l}\text { Double layers } \\
\text { with cut-off bars }\end{array}$ & $180-350$ & $300-500$ & $1.9-3.6$ & $22.9-66.9$ & $1.65-3.31$ & $0.29-1.14$ \\
\hline
\end{tabular}

${ }^{*}$ Shear span to depth ratio, where $d$ is a distance between extreme concrete compressive fiber and centroid of tensile reinforcement.

Notes: $f_{c m}$ is measured compressive strength of concrete cylinder; $\rho_{w}$ is tensile reinforcement ratio; $\rho_{t}$ is transverse reinforcement ratio.

Miyata et al. 2018). This procedure is applicable to a beam in which some of the bars in the second layer are terminated in the span; in this case, $j_{e X}$ is the distance between the centroids of the top and the bottom longitudinal bars at section X. Table 2 includes such a beam.

Takami and Eto (1999) conducted tests of beams with more than two layers of longitudinal bars as shown in the top of Fig. 16: the test parameter was the number of bar layers from one to five. Four deformed bars were arranged in each layer, and the beams were subjected to anti-symmetric bending. The concrete strength of specimens $1-4$ was identical $(68.4 \mathrm{MPa}=9900 \mathrm{psi})$ and that of specimen 5 was slightly higher $(73.7 \mathrm{MPa}=$ 10700 psi). All the specimens failed in bond splitting at

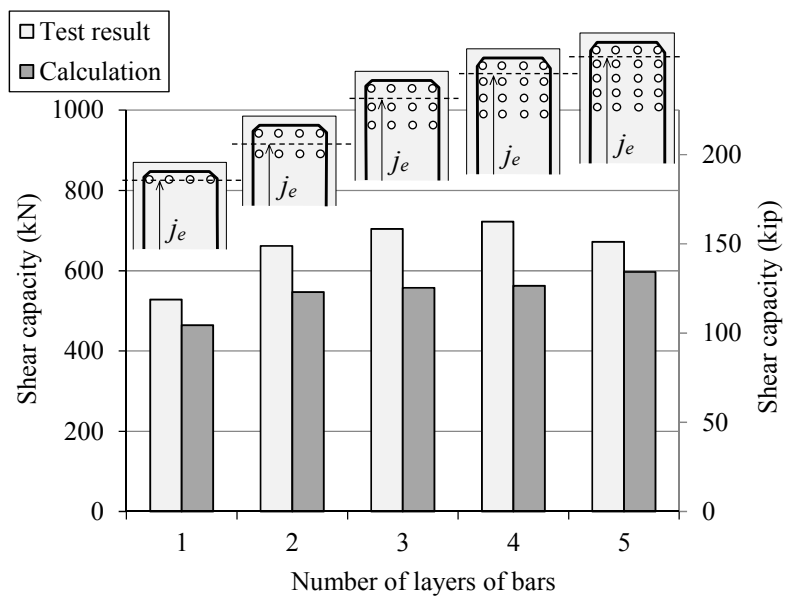

Fig. 16 Shear capacity of beams with multi-layered reinforcing bars. the innermost layer before yielding of longitudinal bars. The light-gray bars in Fig. 16 show the test results: the strengths of the beams with two to five layers were similar each other and were larger than that with one layer. The dark-gray bars in Fig. 16 show the calculation results using Eqs. 2 and 5, where $j_{e}$ for the beams with multi-layers is assumed to be the distance between the centroids of bars in the extreme two layers of the top and the bottom longitudinal bars. The calculations agree reasonably with the test results.

In short, it is proposed that the shear capacity of a beam with multiple layers of bars including cut-off bars is given as follows.

(1) The shear capacity of beam, $V_{s u}$, is the minimum value calculated by Eq. 5 at every section in the span (Fig. 15).

(2) The shear stress on the innermost potential failure plane $\tau_{s u}$ is calculated by Eq. 2 .

(3) The depth $j_{e}$ is assumed as the distance between the centroids of bars in the most extreme two layers (the first and the second layers) of the top and the bottom longitudinal bars (Figs. 14d and 16).

In order to grasp the meaning of Eqs. 2 and 5, let us consider the following case: $\lambda=1$ (normal weight concrete), $\alpha_{t}=0.9$ (top bar) and $N_{t} / N=0.5$ (Fig. 11). If we assume $\alpha_{l}=1.0$ (single layer) and $j_{e} / d=0.9$, we get:

$$
V_{s u}=\left(0.27 \sqrt{f_{c}{ }^{\prime}}+220 \rho_{t}\right) b d \quad(\mathrm{MPa})
$$

If we assume $\alpha_{l}=1.5$ (multi-layer) and $j_{e} / d=0.8$, we get: 


$$
V_{s u}=\left(0.36 \sqrt{f_{c}{ }^{\prime}}+220 \rho_{t}\right) b d \quad(\mathrm{MPa})
$$

The purple and green broken lines in Fig. 17a show the relationship given by Eqs. $7 \mathrm{a}$ and $7 \mathrm{~b}$, respectively. They are parallel each other.

If we assume a beam with tensile reinforcement ratio $=2 \%$ and moderate shear reinforcement, the shear strength given by ACI 318-19 is:

$$
V_{n}=\left[0.17 \sqrt{f_{c}{ }^{\prime}}+\rho_{t} \times \min \left(f_{y t}, 552\right)\right] b d \quad(\mathrm{MPa})
$$

The black line in Fig. 17a shows the relationship, where the upper limit of the second term is considered. Size effect is neglected for simplicity. Note that the inclination of the black line is steeper than those of the broken lines because 220 in Eqs. $7 \mathrm{a}$ and $7 \mathrm{~b}$ is smaller than $f_{y t}$ of grade 40 bar $\left(f_{y t}=276 \mathrm{MPa}\right)$.

The blue and red solid lines in Fig. 17b show the relationship between shear strength and reinforcement given by ACI 318-19 for normal and high strength shear reinforcement, respectively. Figure $\mathbf{1 7 b}$ implies that beams with high strength shear reinforcement and single layer tend to fail in bond splitting.

Figures 17a and $\mathbf{1 7 b}$ can be interpreted as follow:

(1) Concrete in a beam such as Figs. 14 or 15 is subjected to shear stress shown in Fig. 18a.

(2) If stirrups are scarce and have moderate yield strength, tensile failure shown in Fig. 18b may occur with the yielding of stirrups, which corresponds the region of small $\rho_{t}$ in Fig. 17.

(3) If stirrups are abundant and the strength of concrete is insufficient, diagonal compression failure (Fig. 18c) or vertical sliding shear failure (Fig. 18d) may occur, which corresponds the region of large $\rho_{t}$ in
Fig. 17.

(4) If stirrups are moderate and have high yield strength, horizontal shear failure (Fig. 18e) at the plane of longitudinal reinforcement may occur as discussed in this paper.

\section{Verification}

In order to verify the proposed method, fifty-seven beam specimens were chosen from the previous studies (Ito et al. 2013; Shinohara and Murakami 2014, 2015; Takami and Eto 1999; Suzuki et al. 2015; Kamitani et al. 2001; Katori et al. 1988; Kaminosono et al. 1992; Kim et al. 2002; Masuda et al. 1996; Takeuchi et al. 1993; Miyata et al. 2018), as summarized in Table 2. All the specimens were subjected to anti-symmetric bending, and failed in bond-splitting before the yielding of the transverse reinforcement. More than $70 \%$ of the beam specimens listed in Table 2 had stirrups higher than 700 $\mathrm{MPa}(=100 \mathrm{ksi})$. Specimens that failed in shear were not included in the table because of the following reasons:

(1) There are many methods to predict shear strength of beam.

(2) The proposed method can be used in combination with any methods.

(3) If we include specimens that failed in shear, we need to compute their strength in combination with a particular method for shear, which makes the verification process unclear because it depends on the accuracy of the method for shear.

Figure 19a shows the verification for the beam specimens with single-layered continuous reinforcement The numerator $V_{\text {exp }}$ on the vertical axis of Fig. 19a shows the observed shear capacities. The denominator

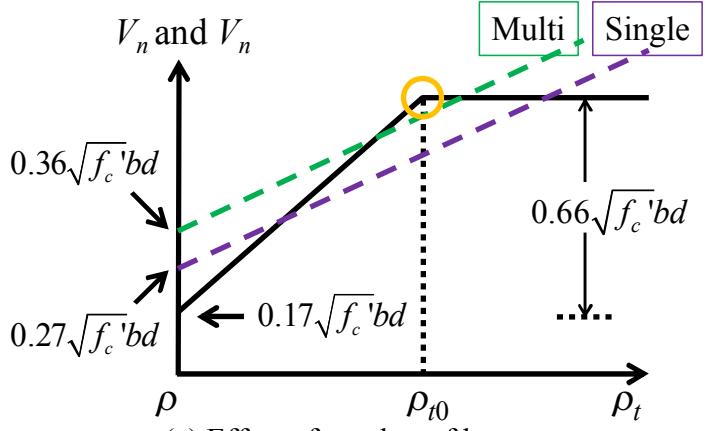

(a) Effect of number of layers

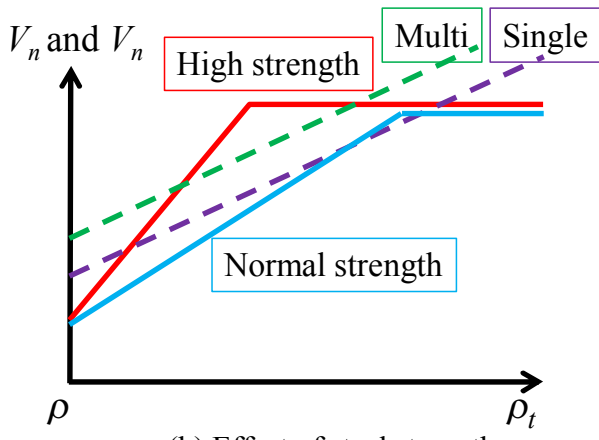

(b) Effect of steel strength

Fig. 17 Schematic relationship between shear strength and reinforcement.

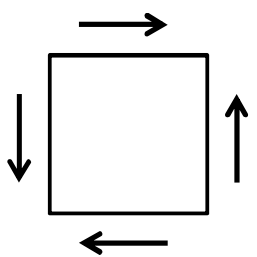

(a) Shear stress

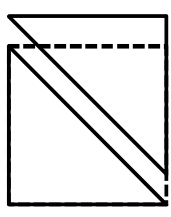

(b) Diagonal tension failure

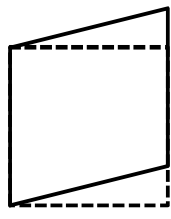

(c) Shear failure

in hinge region

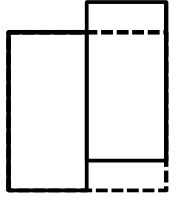

(d) Sliding shear failure

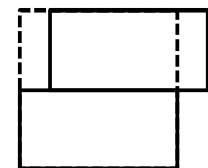

(e) Bond

failure

Fig. 18 Shear stress and probable failures. 
$V_{f}$ shows the flexural capacity of the beams calculated using the following equations:

$$
\begin{aligned}
& V_{f}=M_{f} / l_{s} \\
& M_{f}=0.9 d A_{s} f_{y}
\end{aligned}
$$

In the above equations, $M_{f}$ is the bending moment at yield; $l_{s}$ is one half of the clear span of each beam specimen; $f_{y}$ is the yield strength of tensile reinforcement; $A_{s}$ is the total cross-sectional area of tensile reinforcement; and $d$ is the distance between the centroid of tensile reinforcement and compressive extreme fiber of concrete.

The numerator $V_{s u}$ on the horizontal axis of Fig. 19a shows the shear capacities calculated in accordance with Eq. 5. The mean value and the coefficient of variation (c.o.v.) of the ratios of measured to calculated strengths $\left(V_{\text {exp }} / V_{\text {su }}\right)$ are also shown in the figures. Good agreement is observed except the data enclosed by two circles. The two specimens enclosed by the red circle in Fig. 19a had special features: low strength concrete (27 and 29 $\mathrm{MPa}=4000 \mathrm{psi}$ ) and high shear reinforcement ratio $(1.2 \%)$, which effect is discussed later. The concrete strength of the specimen enclosed by the blue circle in Fig. 19a was again low (23 $\mathrm{MPa}=3300 \mathrm{psi})$.

Figure 19b is similar to Fig. 19a except that the numerator $V_{n}$ on the horizontal axis shows the shear capacities calculated by ACI 318-19 provisions where $V_{c}$ is based on the detailed method considering the effect of tensile reinforcement ratio and $V_{s}$ is computed considering the limitation of $550 \mathrm{MPa}(80 \mathrm{ksi})$ for shear reinforcement according to Table 20.2.2.4(a) in the provisions. The mean value in Fig. 19b (0.98) is smaller than unity, indicating that ACI 318-19 provisions are not conservative.

The vertical axis of Fig. 19c represents the ratio of the observed strength $V_{\text {exp }}$ and the capacity calculated by ACI 318-19 provisions $V_{n}$. The horizontal axis is the shear reinforcement ratio of each specimen divided by $\rho_{t 0}$ defined by the orange circle in Fig. 17a. The $V_{\text {exp }} / V_{n}$ ratio is the lowest around $\rho_{t} / \rho_{t 0}=1.0$; this agrees with Fig. 17a because the broken line is most distant from the solid line at $\rho_{t}=\rho_{t 0}$.

Figures 20a through 20c are for multi-layered beams with continuous reinforcement. Figures 21a through 21c are for double-layered beams with cut-off bars in the second layer. The mean value in Fig. 20b (1.16) is larger than that in Fig. 19b (0.98); this tendency agrees with Fig. 17b. The mean value in Fig. 21b (1.07) is smaller than that in Fig. 20b (1.16); this tendency agrees with the fact that most of the beam specimens with cut-off bars listed in Table 2 had continuous bars only in the first (outer) layer and exhibited bond failure at the first layer as shown in Fig. 13. For the proposed method (Figs. 19a-21a), the mean ratios of measuredto-calculated capacity are larger than 1.1 and the c.o.v.'s

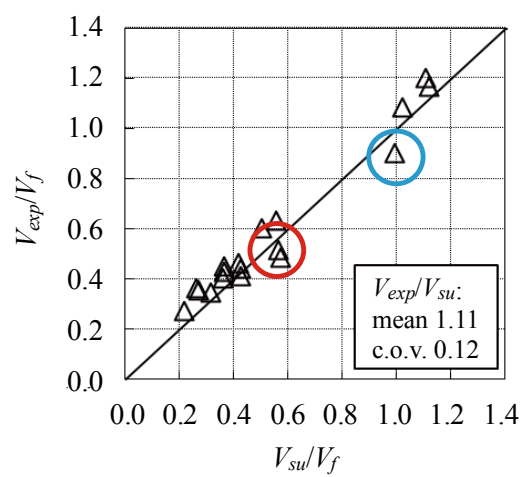

(a) Test results vs. Eq. 5

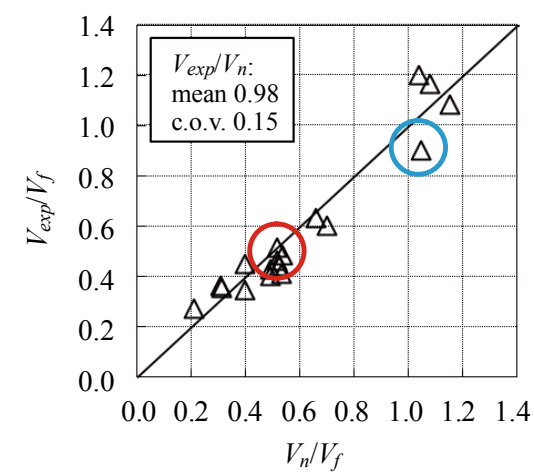

(b) Test results vs. ACI 318

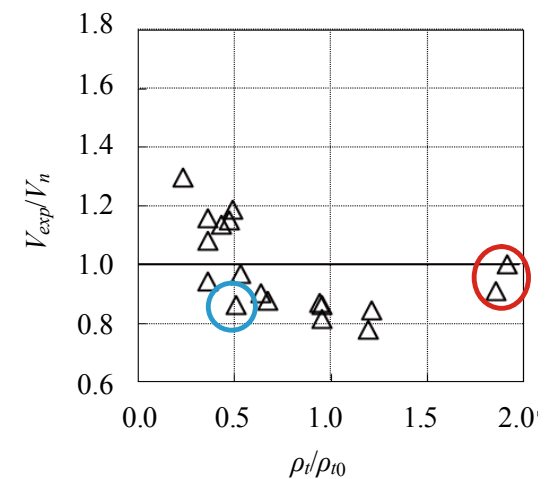

(c) Test results / ACI 318

Fig. 19 Single-layered beams without cut-off bars.

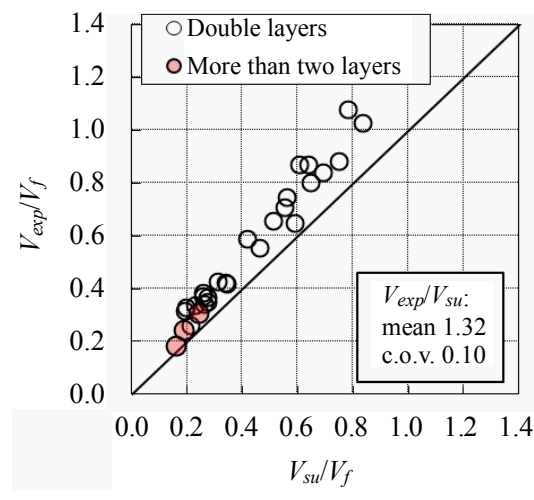

(a) Test results vs. Eq. 5

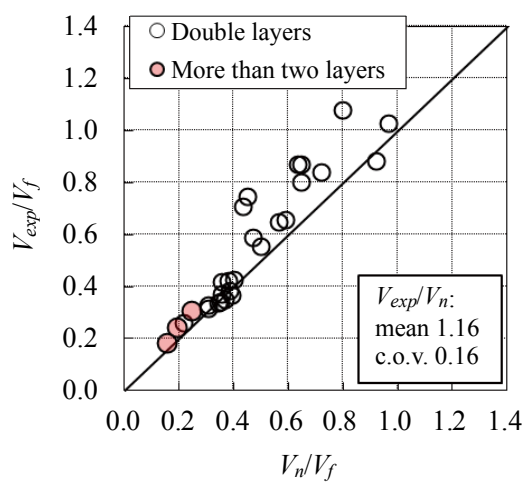

(b) Test results vs. ACI 318

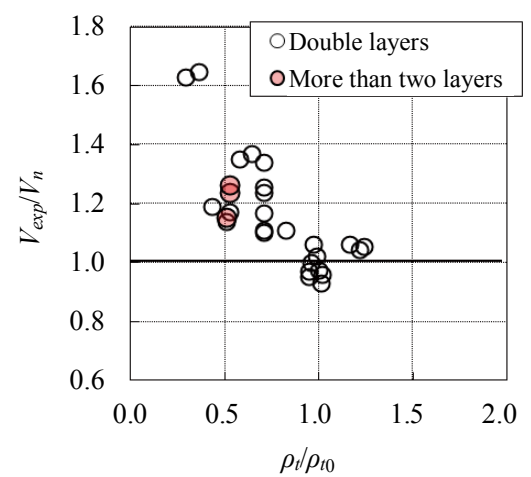

(c) Test results / ACI 318

Fig. 20 Multi-layered beams without cut-off bars. 
Table 3 Column specimens failed in bond-splitting in previous study.

\begin{tabular}{|c|c|c|c|c|c|c|c|c|}
\hline Ref. & Section & $\begin{array}{c}b=D \\
\mathrm{~mm}\end{array}$ & Longitudinal bars & $M /(V h)$ & $P /\left(A_{g} f_{c m}\right)$ & $\begin{array}{l}f_{c m}, \\
\mathrm{MPa}\end{array}$ & $\rho_{t}(\%)$ & $\begin{array}{c}f_{y t} \\
\mathrm{MPa}\end{array}$ \\
\hline \multirow{5}{*}{ Oribe et al. 2021} & & \multirow{5}{*}{350} & \multirow{3}{*}{ 16-D16 } & \multirow{5}{*}{1.5} & 0.10 & 23.2 & 1.1 & \multirow{5}{*}{866} \\
\hline & & & & & 0.25 & 31.4 & 0.8 & \\
\hline & & & & & 0.25 & 34.6 & 1.1 & \\
\hline & & & \multirow[t]{2}{*}{$f_{y}=787 \mathrm{MPa}$} & & 0.30 & 63.0 & 0.8 & \\
\hline & & & & & 0.25 & 66.0 & 1.1 & \\
\hline \multirow{4}{*}{ Oribe et al. 2021} & & \multirow{4}{*}{450} & \multirow{4}{*}{$\begin{array}{c}24-\mathrm{D} 16 \\
f_{y}=818 \mathrm{MPa}\end{array}$} & 2.0 & 0.35 & 28.8 & 1.0 & \multirow{4}{*}{889} \\
\hline & & & & \multirow{3}{*}{1.5} & 0.20 & 55.3 & 0.6 & \\
\hline & & & & & \multirow[b]{2}{*}{0.10} & \multirow[b]{2}{*}{59.9} & \multirow[b]{2}{*}{1.0} & \\
\hline & & & & & & & & \\
\hline
\end{tabular}

Notes: $P$ is applied axial force; $A_{g}$ is gross area of column section.

are smaller than those of ACI 318.

Figure 21 does not include beam specimens with extremely short development length that causes pullout of cutoff bars. Traditional provisions for development length are still required to prevent such pullout.

Table 3 lists column specimens which were subjected to anti-symmetric bending and failed in bond-splitting before the yielding of the transverse reinforcement. Figure 22a shows the comparisons between the test results and calculations: the denominator $V_{f}$ includes the effect of axial force. The red circle in Fig. 22a indicates the data with the ratio of $V_{\text {exp }} / V_{s u}=0.82$, which is smaller than any data in Figs. 19a-21a. This specimen had special features as highlighted in yellow in Table 3: low strength concrete $(23 \mathrm{MPa}=3400 \mathrm{psi})$ and high shear reinforcement ratio (1.1\%). As shown in Fig. 17, the proposed method does not have upper limit as the conventional shear strength equation. The red circle in Fig. 22c indicates $V_{\text {exp }} / V_{n}=0.94$ for this data. The ratios of $V_{\text {exp }} / \min \left(V_{n}, V_{s u}\right)$ for the data enclosed by the red and blue circles in Fig. 19 are also larger than 0.91. It is therefore concluded that the combinational use of current shear strength equations $\left(V_{n}\right)$ and the proposed method $\left(V_{s u}\right)$ provides acceptable prediction.

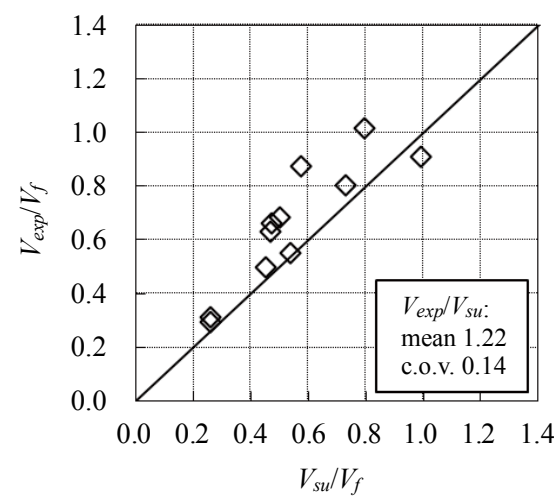

(a) Test results vs. Eq. 9

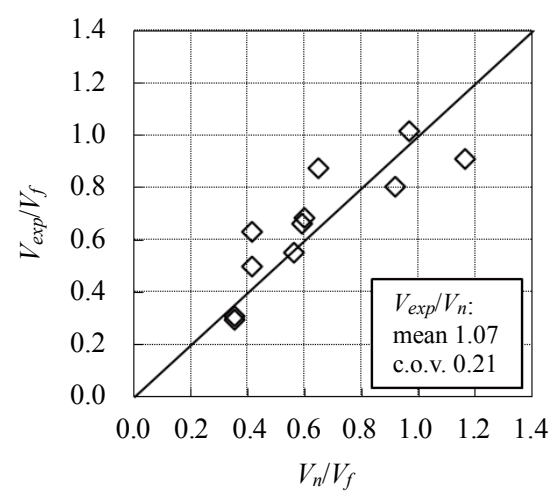

(b) Test results vs. ACI 318

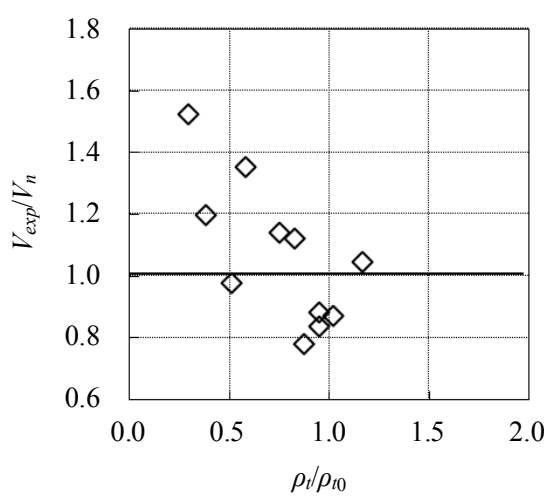

(c) Test results / ACI 318

Fig. 21 Double-layered beams with cut-off bars.

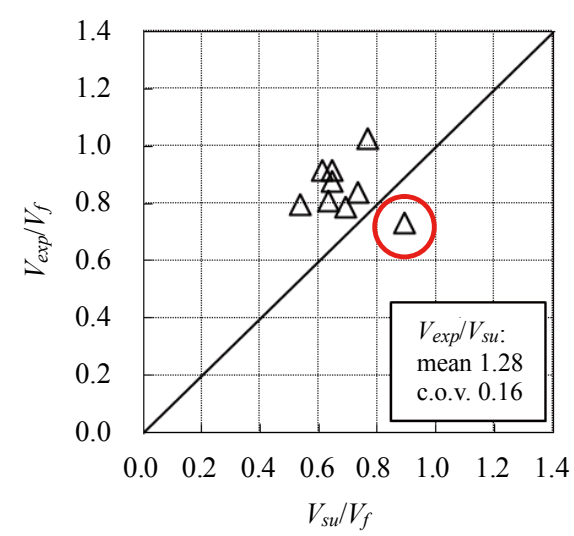

(a) Test results vs. Eq. 9

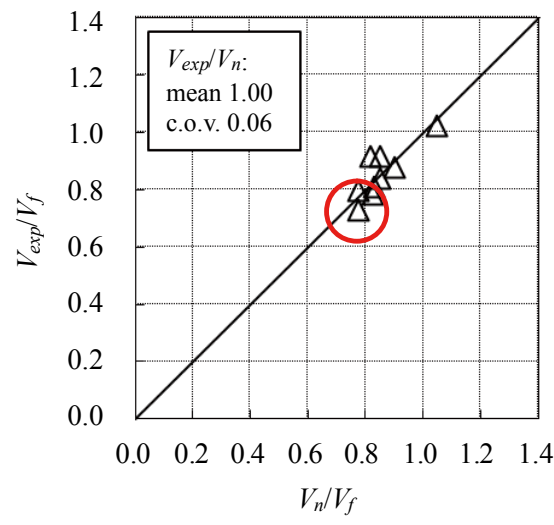

(b) Test results vs. ACI 318

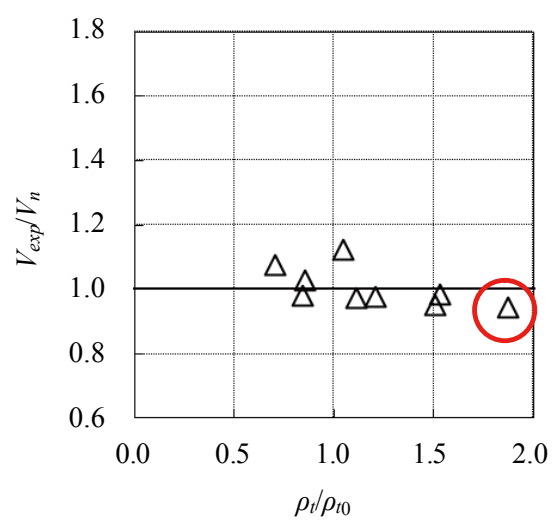

(b) Test results / ACI 318

Fig. 22 Columns which failed in bond splitting 


\section{Further research need}

As indicated by the red circles in Figs. 19a and 22a, Eq. 2 should have an upper limit. The limit may be dependent on $\alpha_{t}$ and $\alpha_{l}$, which are smaller for top bars and larger for multiple-layer bars, respectively, as opposed to the upper limit for shear in ACI 318 (ACI 2019).

The proposed method has been verified only for specimens tested under anti-symmetric bending shear with uniform shear force. However, the shear force of any beam is not uniform because of gravity loads. If we consider the discussion by Marti (1986), applying Eq. 5 to a beam with large gravity loads and small seismic force seems too conservative. Further discussion is needed.

The proposed method has not been verified for specimens with slab, prestress or circular section. Further verification is recommended.

The last topic is ductility. The proposed method does not prevent splitting bond failure after flexural yielding. Further research is needed whether a similar approach is possible to prevent such failure.

\section{Conclusion}

Pullout test results from previous studies were reviewed in this paper and were used as a basis for developing a new method to evaluate bond splitting strength. As an alternative to the traditional method in which bond stress on bar surfaces are evaluated for each bar, Equation 2 was proposed to evaluate the shear capacity of a failure plane below the bond-splitting plane (Fig. 6). The formula was used to calculate shear capacities of RC beams with or without cut-off bars (Eq. 5). The method was successfully applied to most of beam and column specimens which failed in bond splitting prior to the yielding of longitudinal reinforcement (Figs. 19a22a). It is concluded that side splitting failure of $R C$ beams and columns under seismic action can be treated as shear failure. The provisions in ACI 318-19 (ACI 2019) slightly underestimated some of the test results of single-layered beams (Fig. 19b).

\section{Acknowledgments}

The authors thank Dr. Yukinobu Kurose for providing the initial idea of the research, Dr. Naoki Ohnishi for helping the research, and Dr. Lucas A. Laughery for providing advice on the writing.

\section{References}

Abrams, D. A., (1913). "Test of bond between concrete and steel." University of Illinois Engineering Experiment Station Bulletin, Illinois: University of Illinois at Urbana-Champaign, 71.

ACI, (2019). "Building code requirements for structural concrete (ACI 318-19) and commentary." American Concrete Institute.
AIJ, (1999). "Design guidelines for earthquake resistant reinforced concrete buildings based on inelastic displacement concept." Tokyo: Architectural Institute of Japan, 440. (in Japanese, with English summary)

AIJ, (2018). "AIJ standard for structural calculation of reinforced concrete structure." Tokyo: Architectural Institute of Japan, 525. (in Japanese, with English summary)

Canbay, E. and Frosch, R. J., (2005). "Bond strength of lap-spliced bars.” ACI Structural Journal, 102(4), 605-614.

Fujii, S. and Morita, S., (1982). "Splitting bond capacities of deformed bars, Part 1 Experimental studies on main factors influencing splitting bond failure," Transactions of the Architectural Institute of Japan, 319, 47-55. (in Japanese)

Goto, Y., (1971). "Cracks formed in concrete around deformed tension bars." ACI Journal Proceedings, 68(4), 244-251.

Hardisty, J. N., Villalobos, E., Richter, B. P. and Pujol, S., (2015). "Lap splices in unconfined boundary elements." Concrete International, 35(1), 51-58.

Ichinose, T., (1995). "Splitting bond failure of $\mathrm{R} / \mathrm{C}$ columns under seismic action," ACI Structural Journal, 92(5), 535-542.

Ito, A., Hasegawa, K., Suzuki, Y., Takahashi, S. and Ichinose, T., (2013). "Splitting bond strength of RC beam of which second layer bars are cut off." Journal of Structural and Construction Engineering (Transactions of AIJ), 78(690), 1477-1484. (in Japanese)

Jirsa, J. O., Lutz, L. A., and Gergely, P., (1979). "Rationale for suggested development, splice, and standard hook provisions for deformed bars in tension." Concrete International, 1(7), 47-61.

Kaminosono, T., Fujii, S, Furukawa, J. and Fujitani, H., (1992). "Bond split failure and deformation of high strength concrete beams, Part 1 Outline an results of test." Summaries of Technical Papers of Annual Meeting, Architectural Institute of Japan, C, Structures II, 925-926. (in Japanese)

Kamitani, K., Kim, K., Sato, Y. and Fujii, S., (2001). "Effect of shear span ratio and reinforcing arrangement on shear and bond capacities of RC beams, Part 1 Test result." Summaries of Technical Papers of Annual Meeting, Architectural Institute of Japan, C-2, Structures IV, 287-288. (in Japanese)

Katori, K., Nitta, T., Okude, H., Takagi, H. and Kanoh, Y., (1988). "Bond split failure of RC structures with shear reinforcement of difference strength, Part 1 Test and results," Summaries of Technical Papers of Annual Meeting, Architectural Institute of Japan, C, Structures II, 367-368. (in Japanese)

Kim, K., Kamitani, K., Sato, Y. and Fujii, S., (2002). "Influence of rebar cutoff on shear and bond capacities of RC beams," Summaries of Technical Papers of Annual Meeting, Architectural Institute of Japan, C-2, 287-288. (in Japanese) 
Marti, P., (1986). "Staggered shear design of simply supported concrete beams." ACI Journal Proceedings, 83(1), 36-42.

Masuda, H., Shu, R., Tsuihiji, K., Takagi, H. and Kanoh, Y., (1996). "Bond-splitting failure of beams with double-layered-longitudinal reinforcement." Summaries of Technical Papers of Annual Meeting, Architectural Institute of Japan, C-2, Structures IV, 621-622. (in Japanese)

Masuda, H., Tsuihiji, K., Takagi, H. and Kanoh, Y., (1994). "Splitting-bond failure at inner rebars of double-layered longitudinal reinforcements, Part 3 Outlines of test and test results," Summaries of Technical Papers of Annual Meeting, Architectural Institute of Japan, C, Structures II, 645-646. (in Japanese)

Miyata, H., Sasao, T., Kawasaki, M., Yagi, S., Kusuhara, F. and Ichinose, T., (2018). "Effects of cut-off bars on RC beams with high strength reinforcement and concrete, Part 1 Outline of experiment and loaddeformation relationship." Summaries of Technical Papers of Annual Meeting, Architectural Institute of Japan, Structures IV, 225-226. (in Japanese)

Muguruma, H. and Watanabe, F., (1984). "Study on shear mechanisms in R/C short column, Part 2 Failure due to bond splitting." Transactions of the Architectural Institute of Japan, 341, 11-18. (in Japanese)

Nagaya, A., Hotta, K., Kato, Y., Takahashi, S., Pujol, S., Maeda, M. and Ichinose, T., (2013). "Damage of RC building with coupled shear walls caused by the 2011 Great East Japan Earthquake." 10th International Conference on Urban Earthquake Engineering, Tokyo Institute of Technology, Tokyo, Japan.

Nishimura, K. and Onishi, N., (2018). "Experimental study on bond strength in $\mathrm{R} / \mathrm{C}$ beams with double layered cutoff bars." 11th National Conference on Earthquake Engineering (11NCEE), Los Angeles, Paper ID. 853.

Nishimura, K. and Kawazu, M., (2020). "Experimental study on local bond failure of tension reinforcing bars embedded in concrete." Japan Architectural Review, Architectural Institute of Japan, 3(3), 318-333. Available from: https://onlinelibrary.wiley.com/doi/pdf/ 10.1002/2475-8876.12154

Ohyado, M., Iwakura, T., Kanakubo, T., Hirosawa, M., Fujisawa, M. and Sonobe, Y., (1991). "Bond splitting strength of concrete element with double-Layer reinforcing, Part 1 Outline of experiment and bond splitting strength of light-weight concrete." Summaries of Technical Papers of Annual Meeting, Architectural Institute of Japan, C, Structures II, 349350. (in Japanese)

\section{Appendix: bond capacity formula based on AlJ code}

In the first part of this appendix, we transform the bond strength formula in the AIJ Guidelines into a shear
Oribe, Y., Hibino, Y., Ichinose, T., Miyata, H., Kaneko, K. and Kusuhara, F., (2021). "Evaluation of ultimate shear strength of RC members with high-strength shear reinforcement based on establishment condition of truss mechanism." Proceedings of AIJ Chugoku Architectural Research Conference, 44, 81-84. (in Japanese)

Otani, S. and Maeda, M., (1994). "An equation for bond splitting strength based on bond action between deformed bars and concrete, Part 2 A proposal an equation for bond splitting strength." Summaries of Technical Papers of Annual Meeting, Architectural Institute of Japan, C, Structures II, 657-658. (in Japanese)

Schlaich, J., Schafer, K. and Jennewein, M., (1987). "Toward a consistent design of structural concrete." PCI Journal, 32(3), 74-150.

Shinohara, Y. and Murakami, K., (2014). "Bond behaviors of second layer-cutoff bars reinforced by transverse bars having various configurations." Journal of Structural and Construction Engineering (Transactions of AIJ), 79(706), 1887-1897. (in Japanese)

Shinohara, Y. and Murakami K., (2015). "Effect of transverse reinforcement on bond splitting behaviors of RC beams with second layer-cutoff bars." Journal of Structural and Construction Engineering (Transactions of AIJ), 80(714), 1297-1306. (in Japanese)

Sokoli, D. and Ghannoum, J., (2016). "High-strength reinforcement in columns under high shear stresses." ACI Structural Journal, 113(3), 605-614.

Suzuki, T., Uno, K., Takahashi, S. and Ichinose, T., (2015). "Shear strength and bond behavior of RC beam of which second layered bars are cut-off, Part 1 Outline of experiment and discussion of strength." Summaries of Technical Papers of Annual Meeting, Architectural Institute of Japan, Structures IV, 511512. (in Japanese)

Takami, S. and Eto, H., (1999). "A study on bond splitting strength for $\mathrm{R} / \mathrm{C}$ beams of multi-layer reinforcement," Summaries of Technical Papers of Annual Meeting, Architectural Institute of Japan, C-2, Structures IV, 507-508. (in Japanese)

Takeuchi, K., Kanakubo, T., Fujisawa M. and Sonobe Y., (1993). "Development on high strength reinforcement of electric furnace, Part 12 Bond performance of beams with double layer reinforcement." Summaries of Technical Papers of Annual Meeting, Architectural Institute of Japan, C, Structures II, 109-110. (in Japanese)

strength formula to be used at the failure plane. It is compared with ACI 318 (ACI 2019). Next, we extend the formula for double-layered arrangements.

The Inelastic Concept Guidelines (AIJ 1999) by AIJ 
provides the bond strength formula for side-splitting failure in the outer (first) layer of tensile reinforcing bars as follows:

$$
\begin{array}{r}
\tau_{b u}=\lambda \alpha_{t}\left[\left\{0.085\left(\frac{b}{N_{1} d_{b}}-1\right)+0.1\right\} \sqrt{f_{c}{ }^{\prime}}\right. \\
\left.+45\left(1.2+\frac{N_{w}}{N_{1}}\right) \frac{b \rho_{t}}{N_{1} d_{b}}\right]
\end{array}
$$

where

$\lambda, \alpha_{t}, \alpha_{t}, f_{c}$, and $\rho_{t}$ are defined at Eq. 2 and $b$ : beam width $(\mathrm{mm})$,

$d_{b}$ : nominal diameter of longitudinal bar $(\mathrm{mm})$,

$N_{1}$ : the number of bars in first layer,

$N_{w}$ : the number of transverse bars crossing potential splitting plane of $b s$,

The first term in Eq. 11 indicates the contribution of concrete. Because $\left(b-N_{1} d_{b}\right)$ represents the remainder of the beam width minus the total of the bar diameters, $\left(b-N_{1} d_{b}\right) / N_{1}$ is similar to the average of clear spacing of bars. Note that the first term is not proportional to $\left(b-N_{1} d_{b}\right) / N_{1}$ but has a constant of 0.1 . Equation given by Jirsa et al. (1979), which also uses clear spacing to evaluate bond strength also includes similar constant. Interestingly, the equation to determine development length in Chapter 25 of ACI 318 (ACI 2019) uses center-to-center spacing and does not include such a constant. One may rewrite Eq. 11 as follows.

$$
\begin{aligned}
\tau_{b u}=\lambda \alpha_{t}[0.085( & \left.\frac{b}{N_{1} d_{b}}+0.176\right) \sqrt{f_{c}{ }^{\prime}} \\
& \left.+45\left(1.2+\frac{N_{w}}{N_{1}}\right) \frac{b \rho_{t}}{N_{1} d_{b}}\right]
\end{aligned}
$$

We note that 0.176 is usually much smaller than $b /\left(N_{1} d_{b}\right)$; in the case of the specimens listed in Table 1, $b /\left(N_{1} d_{b}\right)$ is between 3.5 and 4.6. We therefore neglect 0.176 and simplify Eq. 12 as follows:

$$
\tau_{b u}=\lambda \alpha_{t} \frac{b}{N_{1} d_{b}}\left[0.085 \sqrt{f_{c}{ }^{\prime}}+45\left(1.2+\frac{N_{w}}{N_{1}}\right) \rho_{t}\right]
$$

The second term in Eq. 13 indicates the contribution of stirrup, which is similar to $K_{t r} / d_{b}$ in section 25 of ACI 318 (ACI 2019). Note that this term does not include the yield strength of transverse reinforcement because the failure occurs before yielding of transverse reinforcement (Goto 1971; Otani and Maeda 1994). AIJ Guidelines has adopted this principle since 1990 (AIJ 2018).
In ACI code before 2008, the contribution of stirrup included the yield strength of transverse reinforcement (ACI 2019).

Equation 11 was developed by multiplying the original formula by Otani and Maeda (1994) by 0.8 to provide a safety margin. To obtain the average value, Eq. 13 needs to be divided by 0.8 . Furthermore, we need to recall that the bond strength ( $\tau_{b u}$ in Fig. 2a) is defined based on the surface area of the embedded bars $\left(N_{1} \pi d_{b} l_{d}\right)$, whereas the shear strength ( $\tau_{s u}$ in Fig. $\left.6 \mathbf{b}\right)$ is defined based on the area of the failure plane $\left(b . l_{d}\right.$ in Fig. 5a). To convert the bond formula into the shear formula, Eq. 13 need to be divided by $b /\left(N_{1} \pi d_{b}\right)$. Thus, the following equation may provide the mean value for $\tau_{s u}$ for single-layered bars.

$$
\begin{aligned}
\tau_{s u 1} & =\frac{N_{1} d_{b}}{b} \times \frac{\pi}{0.8} \times \tau_{b u} \\
& =\lambda \alpha_{t}\left\{0.33 \sqrt{f_{c}{ }^{\prime}}+180\left(1.2+\frac{N_{w}}{N_{1}}\right) \rho_{t}\right\}
\end{aligned}
$$

In Fig. 8, $\tau_{s u 2}$ 's of double-layered bars were approximately 1.5 times those of single-layered bars at $\rho_{t}=0$. The slope of $\tau_{s u 2}$ with respect to $\rho_{t}$ was insensitive to the number of layers. Thus, the following equation may provide the mean value for $\tau_{s u}$ for double-layered bars.

$$
\tau_{s u 2}=\lambda \alpha_{t}\left\{1.5 \times 0.33 \sqrt{f_{c}{ }^{\prime}}+180\left(1.2+\frac{N_{t}}{N}\right) \rho_{t}\right\}
$$

where $N_{t}$ and $N$ are defined according to Fig. 11 .

In Eq. 14, the number of the bars in the inside layer is assumed to be equal to that in the first layer (Fig. 5b). Next, as shown in Fig. 5c, a beam with fewer bars in the second layer than the first layer is discussed. Let $a_{1}$ be the sum of cross-sectional areas of longitudinal bars in the first layer, and $a_{2}$ be the sum in the second layer (Fig. 5b). In Table 1, the second specimens in Nishimura and Kawazu (2020) had 5-D19 and 3-D19 bars in the first and the second layer, respectively $\left(a_{2} / a_{1}=0.6\right)$. Its failure occurred at the second layer as shown in Fig. 5b. On the other hand, the third specimens in Nishimura's paper (Nishimura and Kawazu 2020) with $a_{2} / a_{1}=0.4$ failed at the first layer as shown in Fig. 5c. We assume that $a_{2} / a_{1}$ $=0.5$ is the threshold: we assume that if $a_{2} / a_{1} \geq 0.5$ then the second layer fails and Eq. 6 is applicable. We also assume that if $a_{2} / a_{1}<0.5$ then $\tau_{s u}$ varies linearly between Eqs. 5 and 6: thus we obtain Equation 2 in the main text. 